\title{
Prognostic risk factors of first recurrence in patients with primary stages I-II cutaneous malignant melanoma - from the population- based Swedish melanoma register
}

J ohan Lyth, Magnus Falk, M. Maroti, H. Eriksson and C. Ingvar

The self-archived postprint version of this journal article is available at Linköping University Institutional Repository (DiVA):

http:/ / urn.kb.se/ resolve?urn=urn:nbn:se:liu:diva-143954

N.B.: When citing this work, cite the original publication.

Lyth, J., Falk, M., Maroti, M., Eriksson, H., Ingvar, C., (2017), Prognostic risk factors of first recurrence in patients with primary stages I-II cutaneous malignant melanoma - from the populationbased Swedish melanoma register, J ournal of the European Academy of Dermatology and Venereology, 31(9), 1468-1474. https:// doi.org/ 10.1111/jdv.14280

Original publication available at:

https:// doi.org/ 10.1111/jdv.14280

Copyright: Wiley (12 months)

http:/ / eu.wiley.com/WileyCDA/ 


\section{Prognostic risk factors of first recurrence in patients with primary stage I-II cutaneous malignant melanoma -from the population-based Swedish melanoma register.}

J. Lyth ${ }^{1}$, M. Falk², M. Maroti ${ }^{3}$, H. Eriksson ${ }^{4,5}$, C. Ingvar ${ }^{6}$

${ }^{1}$ Local Health Care Research and Development Unit, County of Östergötland, Linköping, Sweden

${ }^{2}$ Department of Medical and Health Sciences, Division of Community Medicine, Primary Care, Linköping University, Linköping, Sweden

${ }^{3}$ Department of Oncology, County Hospital Ryhov, Jönköping, Sweden

${ }^{4}$ Department of Oncology and Pathology, Karolinska Institutet, Stockholm, Sweden

${ }^{5}$ Department of Oncology, Karolinska University Hospital, Stockholm, Sweden

${ }^{6}$ Department of Surgery, Skåne University Hospital, Clinical Sciences, Lund University, Lund, Sweden Correspondence to: Johan Lyth, Local Health Care Research and Development Unit, County of Östergötland, SE-581 85 Linköping, Sweden

Phone: +46-10 10387 83, Fax: +46-10 1038501

E-mail: johan.lyth@regionostergotland.se

Short title to be used as a 'running head': Prognostic factors for recurrence in melanoma patients Conflicts of Interest and Source of Funding: The work was supported by the Paulsson trust, Lund University. No conflicts of interest were declared from the authors.

Word count Abstract: 250 (250), Word count Text: 2778 (3000), tables: 2, figures: 1

Key words: malignant melanoma; population-based; melanoma recurrence; metastases; risk factors Abbreviations used: SMR: Swedish Melanoma Register; CMM: Cutaneous Malignant Melanoma; CDW: Care data warehouse in Östergötland; RFS: Recurrence-free survival; DFS: Distant-free survival; CI: Confidence interval; HR: Hazard ratios; SNB: Sentinel node Biopsy; N: Local or Regional Metastases; M: Distant Metastases; SSM: Superficial spreading melanoma; LMM: Lentigo maligna melanoma; NM: Nodular melanoma; ALM: Acral lentiginous melanoma. 


\begin{abstract}
Background: Prognostic factors in patients with localised primary cutaneous malignant melanoma (CMM) are well described. However, prognostic factors for recurrence are less documented.
\end{abstract}

Objectives: The aim of this study was to identify prognostic risk factors for first recurrence in patients with localised stage I-II CMM using population-based data. Methods: This study included 1437 CMM patients registered in one region of Sweden during 1999-2012 followed-up through December 31, 2012. To identify first recurrence of CMM disease, data from a care data warehouse, the pathology and radiology department registries were used. Patients were also followed through a census register and the national Cause of Death Register.

Results: The 5- and 10-year RFS were $85.7 \%$ and $81.2 \%$, respectively. The most common site of first recurrence was regional lymph node metastasis closely followed by distant metastasis. After adjusting for all prognostic factors, women had 50\% lower risk of recurrence than men $(\mathrm{HR}=0.5,95 \%$ CI $0.4-0.7)$ and patients $\geq 75$ had higher risk compared to patients 55-69 years ( $\mathrm{HR}=1.7,95 \%$ CI $1.2-2.5)$. Other significant prognostic factors for risk of recurrence were tumour thickness, presence of ulceration, Clark’s level of invasion and histogenetic type. 
Conclusion: Tumour thickness was found to be the predominant risk factor for recurrence. The prognostic factors for recurrence coincided with prognostic factors for CMM-death. The most common site of first recurrence in stage I-II CMM is regional lymph node (42.8\%) closely followed by distant metastases (37.6\%), a fact which has to be taken into consideration when choosing follow-up strategies. 


\section{Introduction}

The incidence of cutaneous malignant melanoma (CMM) has increased rapidly in the last decades in most western countries ${ }^{1}$. The 5 -year relative survival is $85-90 \%$ in Western Europe ${ }^{2}$. However, the prognosis of the patient is highly dependent on disease stage, where the relative 5-year survival of patients in stage III varies between $40-70 \%$ and reported as low as $10 \%$ for patients in stage $\mathrm{IV}^{3,4}$.

Prognostic factors for death in localised invasive CMM are well documented in various studies across the world and also in studies using data from the populationbased Swedish Melanoma Register (SMR) ${ }^{3,5-9}$. A worse prognosis in patients with localised primary CMM is related to increasing age, male sex, nodular histogenetic type, increasing tumour thickness, presence of tumour ulceration and also presence of mitoses in T1 CMM ${ }^{3,5-9}$. However, few studies have used multivariable analyses to identify prognostic risk factors for first recurrence, including locoregional- and distant metastases in stage I-II CMM patients ${ }^{10-12}$. Most previous studies have used selected hospital-based data but only one has used population-based data ${ }^{10}$. Population-based analyses would demonstrate an unbiased proportion of recurrences and the CMMspecific survival and be of importance in planning customised follow-up strategies for different groups of CMM patients. 
Since 1996 clinicopathological data for all primary CMMs in Sweden has been prospectively collected in the population-based nationwide SMR covering 99\% of all CMM patients in the Swedish cancer registry ${ }^{9}$. The County of Östergötland a region consisting of approximately 5\% of the Swedish population since 1999 registered all health-care contacts in a care data warehouse (CDW) and, in addition, the Department of pathology in Östergötland provides a database with all information on metastases sent to pathology. SMR linked to these databases would therefore be a very useful source in identifying type of CMM recurrence.

The aim of this study was to identify prognostic risk factors for first recurrence in patients with localised stage I-II CMM using population-based regional data.

\section{Materials and methods}

\section{Data collection}

Using the unique 10-digit Swedish personal identity number ${ }^{13}$, the following population-based registers were linked; the Swedish cancer registry, SMR, the Swedish cause of death registry, care data warehouse in Östergötland (CDW), and a census registry. Data were also linked to registries from the Department of Pathology and the Department of Radiology at Linköping University Hospital.

Between 1999 and 2012, 1599 patients with invasive CMMs diagnosed in the County of Östergötland, were identified in the Swedish cancer registry. Twenty-two 
patients with previous CMMs diagnosed before 1999 were excluded. Patients with a positive sentinel node biopsy (SNB) $(n=42)$, patients in clinical stage III $(n=26)$, in stage IV $(n=22)$ or with missing stage at diagnosis $(n=50)$ were also excluded from the analyses. The remaining 1437 stage I-II patients were used in further analyses with follow-up through December 31, 2012 via cause of death registry and the census registry. Patient data were then linked to the SMR to obtain the following variables: clinical stage at diagnosis according to the American Joint Commission on Cancer (AJCC-2009) classification ${ }^{3}$, tumour thickness, ulceration, site of the primary tumour, Clark's level of invasion, histogenetic type and result of SNB.

From CDW, patients with CMM related metastases were identified by ICD-10 codes C77.0-79.9 (secondary tumours). Information about radiotherapy and chemotherapy treatment was identified by ICD-10 codes Z510 and Z511, respectively. From the Department of Pathology, CMM metastases were identified by morphology code M87206 and site of metastases were identified by topology codes. From the Department of Radiology, data was collected in cases of difficulty to assess the information from CDW and from the Department of Pathology. Collected information was classified as 1. Local/satellite/in-transit metastases, 2. Regional lymph node metastasis, 3. Distant skin, subcutaneous, or nodal metastases (M1a), 4. Lung metastases (M1b) or 5. All other visceral metastases (M1c). M1a-c was classified according to the AJCC-2009 classification ${ }^{3}$. If a patient was registered in the Swedish cause of death registry as 
having died of CMM without a registered metastasis the patient was classified as M19 (site unknown) and date of death was used as date of metastasis.

This study was approved by the Regional Ethics review board at Linköping University (2012/303-31).

\section{Statistical analysis}

In all analyses, age was categorised into three groups ( $\leq 54,55-69$ and $\geq 70$ years)

with similar number of patients. Tumour thickness was analysed as a categorical variable grouped as T1 $(\leq 1.0 \mathrm{~mm})$, T2 $(1.01-2.0 \mathrm{~mm})$, T3 $(2.01-4.0 \mathrm{~mm})$ and T4 (>4.0 $\mathrm{mm}){ }^{14}$. In most analyses local/satellite/in-transit metastases and regional lymph node metastasis were combined into locoregional metastases and M1a, MIb, M1c and M19 into distant metastases.

Survival time was calculated from the date of diagnosis until date of the event or to the date of censoring. In the survival analyses, death from CMM was selected as the primary event. Censoring was made at the time point of: patient moved outside the County of Östergötland, death from causes other than CMM, or the cut-off date, December 31, 2012. Time to recurrence was calculated from the date of diagnosis until date of locoregional or distant metastasis, whichever occurred first or the date of censoring. Distant metastasis-free (distant-free) time was calculated from the date of diagnosis until date of distant metastasis or to the date of censoring. 
CMM-specific survival, distant-free survival (DFS) and recurrence-free survival (RFS) were estimated using the method of Kaplan and Meier. Risk of recurrence was analysed in a Cox’s proportional hazard regression presenting the independent prognostic impact for each variable and category. The prognostic impacts were expressed as hazard ratios (HRs) with 95\% CIs.

In patients with localised CMM at diagnosis and later having locoregional metastasis, the increased risk for having distant metastasis was evaluated by introducing a time-dependent variable in a Cox model. Patients were regarded as stage I or II until the time-point of a locoregional metastasis and were then regarded as stage III.

Patients with missing data $(n=54)$ on any of the histopathological variables were excluded from the multivariable analyses. A $\chi 2$ test was used to compare distributions. Statistical significance was indicated by P-values $<0.05$.

\section{Results}

Of the 1437 patients diagnosed with a first primary stage I-II CMM in county of Östergötland between 1999 and 2012, 723 (50.3\%) were women. Men had a median age of 64.5 years at diagnosis compared to 59 years for women. The median tumour thickness was $0.9 \mathrm{~mm}$ for men and $0.8 \mathrm{~mm}$ for women $(\mathrm{p}=0.01)$. The number of patients diagnosed with primary CMMs increased during the study period and $>50 \%$ of the patients were diagnosed between 2008 and 2012. (Table 1) 
A total of 173 patients (12.0\%) had a recurrence, either locoregional or distant. The risk of recurrence was significantly lower for women $8.7 \%$ than for men $15.4 \%$ (p $<0.001$ ) (Table 2). Regional lymph node metastatic CMM (42.8\%) were most common among first recurrences followed by distant metastases (37.6\%) and local/satellite/intransit metastases (19.7\%). The median time after diagnosis of the primary CMM to recurrence was 1.3 years (range $0.1-10.7$ ). Time varied significantly between type of first metastases, where time to locoregional metastases was 1.1 years (range 1.1 - 9.3) and time to distant metastases was 1.9 years (range $0.1-11)(p=0.04)$. Time to first recurrence also varied with tumour thickness, where median time to first metastasis was 2.3 years (range $0.2-9.1$ ) for patients with tumour thickness $\leq 1.0 \mathrm{~mm}$ and 0.8 years (range $0.1-9.3$ ) for patients with tumours thickness $>4.0 \mathrm{~mm}$.

The 5- and 10-year RFS were $85.7 \%$ and $81.2 \%$, respectively. Risk of recurrence varied significantly with age and sex. Women aged 55-69 years had the highest 5-year RFS with 95.5\%. In the multivariable analysis sex was an independent risk factor for recurrence, where women had 50\% lower risk of recurrence than men (HR $=0.5,95 \%$ CI 0.4 - 0.7). There was also a significant higher risk for patients $\geq 75$ compared to patients 55-69 years (HR = 1.7, 95\% CI 1.2 - 2.5) after adjustments for all important histopathological factors. Other significant prognostic factors for the risk of recurrence 
were tumour thickness, presence of ulceration, Clark’s level of invasion, NM and ALM versus SSM. (Table 2)

The 5- and 10-year DFS was 88.8\% and 84.5, respectively. The 5-year DFS varied with sex and age from $97.0 \%$ for women $55-69$ years to $77.0 \%$ for men 75 years or older. In patients with distant metastases, M1c was the most common first site of metastases (65\%) There was no significant difference in distribution of site of metastases between men and women $(\mathrm{p}=0.84)$.

Ninety-nine out of 127 patients with distant metastases were followed at the oncology clinic, Linköping University Hospital, where 75 patients (76\%) received chemotherapy, radiotherapy or both. Chemotherapy was received in 65 of the 75 patients and the median age at the distant metastasis was 62 years (range 29 - 81). The median age for patients without oncologic treatment was 78 years (range 49 - 99) and for patients only receiving radiotherapy was 81 years (range 54 - 88).

Eighteen patients (14\%) with distant metastasis were treated on clinics other than oncology and/or surgical clinics. Seventeen of these patients had no previous locoregional metastasis. The median age at distant metastasis for these patients were 85.5 years (range 66 - 97) representing the elderly patients in the cohort. The median time from diagnosis of the primary CMM to distant metastasis was 1.7 years (range 0.1 - 11) for these patients. 
In patients with locoregional metastases as first recurrence $(n=108), 62(57.4 \%)$ patients subsequently developed distant metastases with a median time of 0.7 years (range 0 - 5.2). Women with locoregional metastases were less likely to develop distant metastases $(44.7 \%)$ than men (64.3) $(p=0.05)$, but there was no significant differences according to age $(\mathrm{p}=0.61)$ or if the first metastasis was a regional lymph node metastasis or a local/satellite/in-transit metastasis $(\mathrm{p}=0.06)$.

In a time-dependent Cox analysis, after adjusting for sex, age, period of diagnosis, site of the primary tumour, histogenetic type, tumour thickness, Clark’s level of invasion and ulceration, a diagnosed locoregional metastatic disease was found to increase the risk of distant metastasis by 13 times ( $\mathrm{HR}=13.2$, 95\% CI 8.7 - 20).

The 5- and 10-year CMM-specific survival was 90.2 and 84.6, respectively. In total 114 (7.9\%) patients died due to CMM. Of these 76 (10.6\%) were men and 38 (5.3\%) women. In 127 patients with distant metastases, 13 were still alive at end of follow-up. Three women and one man with primary stage I-II CMM with a registered CMM-death had no previous recorded metastases. All of these four patients were 86 years or older. Excluding these four patients in an alternative multivariable Cox analysis did not affect the results. 


\section{Discussion}

To our knowledge, this is one of the first population-based reports presenting prognostic factors in a multivariable setting of over 1400 patients with primary stage III CMMs including recurrence data. In the present study, the most important prognostic risk factor for recurrence (locoregional/distant) was increasing tumour thickness. Another important finding was that even after adjusting for age, period of diagnosis, site of primary tumour, histogenetic type, tumour thickness, Clark's level of invasion and tumour ulceration, women had an independent 50\% reduced risk of recurrence compared to men. These differences confirm the results from earlier studies and might be due to behavioural factors with women being diagnosed earlier with primary CMMs 15, 16. Biological sex differences may be of importance specifically in more advanced disease compared to the impact of early detection ${ }^{15,17}$. The prognostic factors found in this study are in accordance with previous studies ${ }^{10-12}$, with somewhat different focus on (T-stage and SNB). Our results shows similar results as another Swedish populationbased study ${ }^{6}$. This indicates that the important prognostic factors for recurrence and CMM-death coincide. The large proportion of patients (114/173) with recurrence actually died from CMM. Although the risk of recurrence was very low in patients with tumour thickness $\leq 1.0 \mathrm{~mm}$, the total number of patients with metastases was almost as high as in patients with tumour thickness $1.01-2.0 \mathrm{~mm}$. This is probably due to the fact 
that the proportion of patients with tumour thickness $\leq 1.0$ has increased over time and now consists of over $50 \%$ of the CMM patients ${ }^{18}$.

Nearly $60 \%$ of patients with locoregional metastases later developed distant metastases. Women with locoregional metastases had somewhat lower risk of later developing distant metastases than men independent of age. A previous study on patients with Stage III at primary diagnosis also showed heterogenic survival outcome between men and women ${ }^{19}$. For patients with distant metastases M1c (65\%) was the dominating site which could be compared to AJCC data (stage IV at primary diagnosis) where the proportion of M1c was $58 \%^{3}$.

In the present study, $37.6 \%$ of the patients with recurrences developed distant metastases without previous locoregional metastases indicating haematogenous metastases ${ }^{20}$. This result falls within the range of proportions found in previous studies (25.3 - 44.9)\%, but varies depending on if the study was population-based or not ${ }^{12,20-}$ ${ }^{25}$. In a previous mentioned Swedish population-based study, this proportion was found to be somewhat lower (32.9\%), but patients with CMM-death without previous metastases were excluded ${ }^{23}$, but in this study included $(n=4)$. In our population-based study a few patients with a registered CMM-death and no previous metastases were included and also patients with metastatic disease with no recorded contact with the Department of Oncology, Linköping University Hospital was included. We find this a 
better reflection of the clinical setting. This report indicates that identifying metastases in an early stage only through clinical examination may be difficult since a relatively high proportion of these CMM patients developed distant metastases without previous locoregional recurrences. Also, the results from this study show that it is difficult to predict distant metastases at the individual level as the first recurrence. CMM is a highly genetically heterogenic disease with a high mutational load which makes it problematic to identify patients at high risk for distant metastases by only using clinical and histopathological factors. Thus prognostic molecular biomarkers are warranted. Considerable differences in CMM follow-up routines worldwide ${ }^{26-30}$ might motivate randomised/health economic studies comparing different follow-up systems. Moreover, during the study period, effective treatment options for metastasised CMMs were limited and also no or few clinical trials using targeted therapies or immune check point blockers were performed in the South-Eastern region of Sweden. The rapid development of effective novel therapies in advanced CMM has also changed the treatment landscape for patients with locoregional disease that may receive neo/adjuvant systemic targeted or immune modulating treatment within or outside clinical trial $^{31-33}$.

A strength with the SMR register is that it has an almost complete coverage of primary CMMs and missing values for important histopathological factors are low. A 
great weakness is unfortunately that no recurrence data are collected in the SMR. This study has shown that recurrence data could be collected from other registries in a region in Sweden with good structured data. A previous Swedish study from the Stockholm/Gotland region studied stage-specific risk of progression/recurrence. ${ }^{10}$ The proportion of patients with metastasis found in that study was somewhat higher compared to our findings, but the inclusion criteria differed as the study included clinical stage III-IV patients and also patients with a positive SNB. Furthermore, the methodology was a bit different; instead of using structured pathology and diagnosis data, they used text-mining algorithms in the patient records at the oncology and pathology departments. Perhaps a combination of the two methodologies could be used to create a faster and more reliable way of collecting metastases data for entire Sweden. The outcome of SNB in patients diagnosed during the early years of the study was not available because SNB was not fully implemented in the national guidelines until 2007. Patients with clinically undetectable lymph node micrometastasis were classified into stages I and II before 2007 and afterwards into stage III CMM, and were therefore excluded from the present analysis. The results in this study are only valid for patients without information of SNB or patients with a negative SNB. A positive SNB significantly increases the risk of recurrence ${ }^{11}$. A recent large population-based study from Sweden also showed that the risk of dying from CMM was three times higher after a positive SNB compared to a negative SNB. ${ }^{6}$ 
Tumour thickness was found to be the predominant risk factor for recurrence. The prognostic factors for recurrence coincided with prognostic factors for CMM-death. The most common site of first recurrence in stage I-II CMM is regional lymph node (42.8\%) closely followed by distant metastases (37.6\%), a fact which has to be taken into consideration when choosing follow-up strategies. 


\section{Acknowledgements}

The work was supported by the Paulsson trust, Lund University. We thank all people reporting patients with cutaneous malignant melanoma to the Swedish melanoma register. 


\section{References}

1. Erdmann F, Lortet-Tieulent J, Schuz J, et al. International trends in the incidence of malignant melanoma 1953-2008-are recent generations at higher or lower risk? Int J Cancer. 2013;132; 385400.

2. De Angelis R, Sant M, Coleman MP, et al. Cancer survival in Europe 1999-2007 by country and age: results of EUROCARE-5-a population-based study. Lancet Oncol. 2013.

3. Balch CM, Gershenwald JE, Soong SJ, et al. Final Version of 2009 AJCC Melanoma Staging and Classification. J Clin Oncol. 2009;27; 6199-6206.

4. Balch CM, Gershenwald JE, Soong SJ, et al. Multivariate analysis of prognostic factors among 2,313 patients with stage III melanoma: comparison of nodal micrometastases versus macrometastases. J Clin Oncol. 2010;28; 2452-2459.

5. Mahar AL, Compton C, Halabi S, et al. Critical Assessment of Clinical Prognostic Tools in Melanoma. Ann Surg Oncol. 2016.

6. Lyth J, Mikiver R, Nielsen K, Isaksson K, Ingvar C. Prognostic instrument for survival outcome in melanoma patients: based on data from the population-based Swedish Melanoma Register. Eur J Cancer. 2016;59; 171-178.

7. Eriksson H, Frohm-Nilsson M, Jaras J, et al. Prognostic factors in localized invasive primary cutaneous malignant melanoma: results of a large population-based study. Br J Dermatol. 2015;172; 175-186.

8. Lyth J, Hansson J, Ingvar C, et al. Prognostic subclassifications of T1 cutaneous melanomas based on ulceration, tumour thickness and Clark's level of invasion: results of a population-based study from the Swedish Melanoma Register. Br J Dermatol. 2013;168; 779-786.

9. Lindholm C, Andersson R, Dufmats M, et al. Invasive cutaneous malignant melanoma in Sweden, 1990-1999 - A prospective, population-based study of survival and prognostic factors. Cancer-Am Cancer Soc. 2004;101; 2067-2078.

10. Rockberg J, Amelio JM, Taylor A, Jorgensen L, Ragnhammar P, Hansson J. Epidemiology of cutaneous melanoma in Sweden - stage specific survival and rate of recurrence. Int J Cancer. 2016.

11. Moehrle M, Schippert W, Rassner G, Garbe C, Breuninger H. Micrometastasis of a sentinel lymph node in cutaneous melanoma is a significant prognostic factor for disease-free survival, distantmetastasis-free survival, and overall survival. Dermatol Surg. 2004;30; 1319-1328.

12. Gimotty PA, Guerry D, Ming ME, et al. Thin primary cutaneous malignant melanoma: a prognostic tree for 10-year metastasis is more accurate than American Joint Committee on Cancer staging. J Clin Oncol. 2004;22; 3668-3676.

13. Ludvigsson JF, Otterblad-Olausson P, Pettersson BU, Ekbom A. The Swedish personal identity number: possibilities and pitfalls in healthcare and medical research. Eur J Epidemiol. 2009;24; 659667.

14. Balch CM, Buzaid AC, Soong SJ, et al. Final version of the American Joint Committee on Cancer staging system for cutaneous melanoma. J Clin Oncol. 2001;19; 3635-3648. 
15. Joosse A, Collette S, Suciu S, et al. Superior outcome of women with stage I/II cutaneous melanoma: pooled analysis of four European Organisation for Research and Treatment of Cancer phase III trials. J Clin Oncol. 2012;30; 2240-2247.

16. Joosse A, Collette S, Suciu S, et al. Sex is an independent prognostic indicator for survival and relapse/progression-free survival in metastasized stage III to IV melanoma: a pooled analysis of five European organisation for research and treatment of cancer randomized controlled trials. J Clin Oncol. 2013;31; 2337-2346.

17. Gamba CS, Clarke CA, Keegan TH, Tao L, Swetter SM. Melanoma survival disadvantage in young, non-Hispanic white males compared with females. JAMA Dermatol. 2013;149; 912-920.

18. Lyth J, Eriksson H, Hansson J, et al. Trends in cutaneous malignant melanoma in Sweden 1997-2011: thinner tumours and improved survival among men. Br J Dermatol. 2015;172; 700-706.

19. Eriksson H, Lyth J, Andersson TM. The proportion cured of patients diagnosed with Stage III-IV cutaneous malignant melanoma in Sweden 1990-2007: A population-based study. Int J Cancer. 2016;138; 2829-2836.

20. Mervic L. Time Course and Pattern of Metastasis of Cutaneous Melanoma Differ between Men and Women. Plos One. 2012;7.

21. Francken AB, Shaw HM, Accortt NA, Soong SJ, Hoekstra HJ, Thompson JF. Detection of first relapse in cutaneous melanoma patients: Implications for the formulation of evidence-based followup guidelines. Ann Surg Oncol. 2007;14; 1924-1933.

22. Meier F, Will S, Ellwanger U, et al. Metastatic pathways and time courses in the orderly progression of cutaneous melanoma. Br J Dermatol. 2002;147; 62-70.

23. Cohn-Cedermark G, Mansson-Brahme E, Rutqvist LE, Larsson O, Singnomklao T, Ringborg U. Metastatic patterns, clinical outcome, and malignant phenotype in malignant cutaneous melanoma. Acta Oncol. 1999;38; 549-557.

24. Soong SJ, Harrison RA, McCarthy WH, Urist MM, Balch CM. Factors affecting survival following local, regional, or distant recurrence from localized melanoma. J Surg Oncol. 1998;67; 228-233.

25. Karakousis CP, Temple DF, Moore R, Ambrus JL. PROGNOSTIC PARAMETERS IN RECURRENT MALIGNANT-MELANOMA. Cancer-Am Cancer Soc. 1983;52; 575-579.

26. Garbe C, Peris K, Hauschild A, et al. Diagnosis and treatment of melanoma. European consensusbased interdisciplinary guideline - Update 2016. Eur J Cancer. 2016;63; 201-217.

27. Bichakjian CK, Halpern AC, Johnson TM, et al. Guidelines of care for the management of primary cutaneous melanoma. American Academy of Dermatology. Journal of the American Academy of Dermatology. 2011;65; 1032-1047.

28. Marsden JR, Newton-Bishop JA, Burrows L, et al. Revised U.K. guidelines for the management of cutaneous melanoma 2010. Br J Dermatol. 2010;163; 238-256.

29. New Zealand Guideline group. Clinical Practice Guidelines for the Management of Melanoma in Australia and New Zealand; 2008.

http://www.cancer.org.au/content/pdf/HealthProfessionals/ClinicalGuidelines/ClinicalPracticeGuideli nes-ManagementofMelanoma.pdf. 
30. Nationellt vårdprogram malignt melanom; 2014.

http://www.cancercentrum.se/samverkan/cancerdiagnoser/hud-och-ogon/vardprogram/.

31. Eggermont AM, Chiarion-Sileni V, Grob JJ, et al. Prolonged Survival in Stage III Melanoma with Ipilimumab Adjuvant Therapy. N Engl J Med. 2016.

32. Robert C, Long GV, Brady B, et al. Nivolumab in previously untreated melanoma without BRAF mutation. N Engl J Med. 2015;372; 320-330.

33. Long GV, Stroyakovskiy D, Gogas H, et al. Dabrafenib and trametinib versus dabrafenib and placebo for Val600 BRAF-mutant melanoma: a multicentre, double-blind, phase 3 randomised controlled trial. Lancet. 2015;386; 444-451. 


\section{Figure legends}

Fig. 1 Melanoma-specific survival, distant-free survival (DFS) and recurrence-free survival (RFS) in 1437 patients diagnosed with primary stage I-II cutaneous malignant melanoma in County of Östergötland 1999-2012

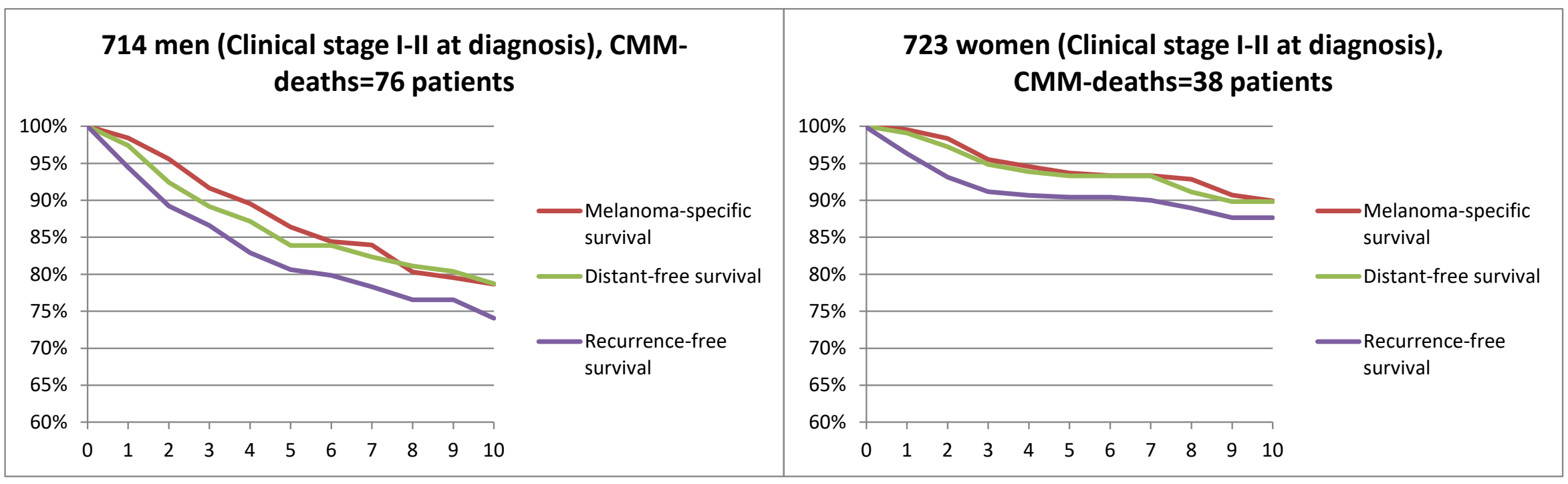




\section{Tables}

Table 1 Patient- and tumour characteristics for $1437^{\mathrm{a}}$ patients diagnosed with primary stage I-II cutaneous malignant melanoma in County of Östergötland 1999-2012

\begin{tabular}{|c|c|c|c|}
\hline Variable & Men & Women & All \\
\hline \multicolumn{4}{|l|}{ Age group } \\
\hline$\leq 54$ & $182(25.5)$ & $277(38.3)$ & 459 (31.9) \\
\hline $55-69$ & $261(36.6)$ & 215 (29.7) & $476(33.1)$ \\
\hline$\geq 70$ & $271(28.0)$ & $231(32.0)$ & $502(34.9)$ \\
\hline Median age (range) & $64.5(19-96)$ & $59(15-97)$ & $63(15-97)$ \\
\hline \multicolumn{4}{|l|}{ Period of diagnosis } \\
\hline 1999-2002 & $141(19.7)$ & $131(18.1)$ & 272 (18.9) \\
\hline $2003-2007$ & $202(28.3)$ & $225(31.1)$ & 427 (29.7) \\
\hline $2008-2012$ & $371(52.0)$ & $367(50.8)$ & $738(51.4)$ \\
\hline \multicolumn{4}{|l|}{ Site of primary tumour } \\
\hline Head/neck & $117(16.4)$ & $96(13.3)$ & $213(14.8)$ \\
\hline Upper extremities & $120(16.8)$ & $158(21.9)$ & $278(19.3)$ \\
\hline Lower extremities & $58(8.1)$ & $237(32.8)$ & $295(20.5)$ \\
\hline Trunk & $411(57.6)$ & $220(30.4)$ & $631(43.9)$ \\
\hline Hand/foot/subungual & $8(1.1)$ & $12(1.7)$ & $20(1.4)$ \\
\hline \multicolumn{4}{|l|}{ Histogenetic type } \\
\hline SSM & $411(58.1)$ & $434(60.4)$ & $845(59.2)$ \\
\hline LMM & $42(5.9)$ & $56(7.8)$ & $98(6.9)$ \\
\hline NM & $155(21.9)$ & $131(18.2)$ & $286(20.0)$ \\
\hline ALM & $5(0.7)$ & $9(1.3)$ & $14(1.0)$ \\
\hline Other types & $95(13.4)$ & $89(12.4)$ & $184(12.9)$ \\
\hline Missing & 6 & 4 & 10 \\
\hline \multicolumn{4}{|l|}{ Tumour thickness, mm } \\
\hline$\leq 1.0$ & $388(54.3)$ & $447(61.8)$ & $835(58.1)$ \\
\hline $1.01-2.0$ & $138(19.3)$ & $124(17.2)$ & $262(18.2)$ \\
\hline $2.01-4.0$ & $124(17.4)$ & $98(13.6)$ & $222(15.4)$ \\
\hline$>4.0$ & $64(9.0)$ & $54(7.5)$ & $118(8.2)$ \\
\hline Median thickness (range) & $0.9(0.1-46)$ & $0.8(0.1-55)$ & $0.9(0.1-55)$ \\
\hline \multicolumn{4}{|l|}{ Clark's level of invasion } \\
\hline II & $209(29.9)$ & $235(32.9)$ & $444(31.4)$ \\
\hline III & $237(34.0)$ & $243(34.0)$ & $480(34.0)$ \\
\hline IV & $237(34.0)$ & $216(30.2)$ & $453(32.1)$ \\
\hline $\mathrm{V}$ & $15(2.1)$ & $21(2.9)$ & $36(2.5)$ \\
\hline Missing & 16 & 8 & 24 \\
\hline \multicolumn{4}{|l|}{ Ulceration } \\
\hline Absent & $540(76.8)$ & $588(83.2)$ & $1128(80.0)$ \\
\hline Present & $163(23.2)$ & $119(16.8)$ & $282(20.0)$ \\
\hline Missing & 11 & 16 & 27 \\
\hline
\end{tabular}

${ }^{\text {a }}$ All patients had clinical stage I or II at diagnosis and 42 patients with positive sentinel node biopsi were excluded 
Table 2 Risk of recurrence for $1437^{\mathrm{a}}$ patients diagnosed with primary stage I-II cutaneous malignant melanoma in County of Östergötland 1999-2012

\begin{tabular}{|c|c|c|c|c|c|}
\hline Variable & $\begin{array}{c}\begin{array}{c}\text { No of } \\
\text { patients }\end{array} \\
\end{array}$ & $\begin{array}{c}\text { No }(\%) \text { of } \\
\text { reccurences }\end{array}$ & $\begin{array}{c}\text { 5-year } \\
\text { Recurrence free } \\
\text { survival (RFS) } \\
\end{array}$ & $\begin{array}{c}\text { Univariable } \\
\text { analysis } \\
\text { HR }(95 \% \mathrm{CI})^{\mathrm{b}} \\
\end{array}$ & $\begin{array}{c}\text { Multivariable } \\
\text { analysis }^{c} \\
\text { HR }(95 \% \mathrm{CI})^{\mathrm{b}} \\
\end{array}$ \\
\hline Total & 1437 & $173(12.0)$ & 85.7 (83.6-87.9) & - & - \\
\hline Sex & & & & $\mathrm{p}<0.001$ & $\mathrm{p}<0.001$ \\
\hline Men & 714 & $110(15.4)$ & $80.6(77.1-84.3)$ & 1.00 (ref) & 1.00 (ref) \\
\hline Women & 723 & $63(8.7)$ & $90.4(88.0-92.9)$ & $0.5(0.4-0.7)$ & $0.5(0.4-0.7)$ \\
\hline Age group & & & & $\mathrm{p}<0.001$ & $\mathrm{p}=0.02$ \\
\hline$\leq 54$ & 459 & $41(8.9)$ & $90.4(87.4-93.5)$ & $0.9(0.6-1.4)$ & $1.5(1.0-2.3)$ \\
\hline $55-69$ & 476 & $46(9.7)$ & $88.4(84.9-92.0)$ & 1.00 (ref) & 1.00 (ref) \\
\hline$\geq 70$ & 502 & $86(17.1)$ & $78.1(73.7-82.8)$ & $2.1(1.4-3.0)$ & $1.7(1.2-2.5)$ \\
\hline Period of diagnosis & & & & $\mathrm{p}=0.04$ & $\mathrm{p}=0.44$ \\
\hline 1999-2002 & 272 & 54 (19.9) & $83.4(79.0-88.1)$ & 1.00 (ref) & 1.00 (ref) \\
\hline $2003-2007$ & 427 & $73(17.1)$ & $83.8(80.3-87.5)$ & $1.1(0.7-1.6)$ & $1.0(0.7-1.5)$ \\
\hline $2008-2012$ & 738 & $46(6.2)$ & $90.0(86.9-93.3)$ & $0.7(0.4-1.0)$ & $0.8(0.5-1.3)$ \\
\hline Site of primary tumour & & & & $\mathrm{p}=0.27$ & $\mathrm{p}=0.99$ \\
\hline Head/neck & 213 & $32(15.0)$ & 80.7 (74.2-87.7) & 1.00 (ref) & 1.00 (ref) \\
\hline Upper extremities & 278 & $31(11.2)$ & 84.9 (79.8-90.3) & $0.7(0.4-1.2)$ & $0.9(0.5-1.6)$ \\
\hline Lower extremities & 295 & $30(10.2)$ & $89.2(85.2-93.3)$ & $0.6(0.3-1.0)$ & $1.0(0.5-1.6)$ \\
\hline Trunk & 631 & $76(12.0)$ & $86.0(82.9-89.3)$ & $0.7(0.5-1.2)$ & $1.0(0.6-1.5)$ \\
\hline Hand/foot/subungual & 20 & $4(20.0)$ & $78.6(62.0-99.6)$ & $1.3(0.4-4.1)$ & $0.8(0.2-3.0)$ \\
\hline Histogenetic type & & & & $\mathrm{p}<0.001$ & $p=0.01$ \\
\hline SSM & 845 & $57(6.7)$ & $92.2(90.0-94.4)$ & 1.00 (ref) & 1.00 (ref) \\
\hline LMM & 98 & $4(4.1)$ & $94.8(89.9-100)$ & $0.7(0.3-2.0)$ & $0.9(0.3-2.7)$ \\
\hline NM & 286 & $93(32.5)$ & $65.7(60.0-72.0)$ & $5.0(3.6-7.0)$ & $1.5(1.0-2.3)$ \\
\hline ALM & 14 & $4(28.6)$ & $65.3(42.3-100)$ & $6.4(2.0-21)$ & $7.1(2.0-25)$ \\
\hline Other types & 184 & $14(7.6)$ & $90.0(84.4-95.9)$ & $1.3(0.7-2.4)$ & $1.0(0.5-2.0)$ \\
\hline Missing & 10 & $1(10.0)$ & $85.7(63.3-100)$ & - & - \\
\hline Tumour thickness. mm & & & & $\mathrm{p}<0.001$ & $\mathrm{p}<0.001$ \\
\hline$\leq 1.0$ & 835 & $27(3.2)$ & $95.9(94.2-97.6)$ & 1.00 (ref) & 1.00 (ref) \\
\hline $1.01-2.0$ & 262 & $34(13.0)$ & $85.0(79.9-90.5)$ & $4.0(2.4-6.7)$ & $2.3(1.2-4.3)$ \\
\hline $2.01-4.0$ & 222 & $60(27.0)$ & $66.2(59.0-74.3)$ & $10(6.3-16)$ & $4.0(2.1-7.6)$ \\
\hline$>4.0$ & 118 & $52(44.1)$ & $51.4(42.3-62.5)$ & $20(12-32)$ & $6.7(3.4-13)$ \\
\hline Clark's level of invasion & & & & $\mathrm{p}<0.001$ & $p=0.13$ \\
\hline II & 444 & $11(2.5)$ & $97.7(96.1-99.4)$ & 1.00 (ref) & 1.00 (ref) \\
\hline III & 480 & $43(9.0)$ & $88.9(85.5-92.5)$ & $4.3(2.2-8.5)$ & $2.1(1.0-4.5)$ \\
\hline IV & 453 & $98(21.6)$ & 74.1 (69.4-79.1) & $11(5.9-22)$ & $2.4(1.0-5.4)$ \\
\hline V & 36 & $14(38.9)$ & 55.7 (40.5-76.7) & $29(13-66)$ & $3.5(1.2-9.6)$ \\
\hline Missing & 24 & $7(29.2)$ & $58.9(38.9-89.3)$ & - & - \\
\hline Ulceration & & & & $\mathrm{p}<0.001$ & $p=0.03$ \\
\hline Absent & 1128 & $83(7.4)$ & 91.7 (89.8-93.7) & 1.00 (ref) & 1.00 (ref) \\
\hline Present & 282 & 87 (30.9) & 62.7 (56.4-69.6) & $4.6(3.4-6.2)$ & $1.5(1.0-2.1)$ \\
\hline Missing & 27 & $3(11.1)$ & $88.7(77.5-100)$ & - & - \\
\hline
\end{tabular}

bold, significant.

${ }^{\text {a }}$ All patients had clinical stage I or II at diagnosis and 42 patients with positive sentinel node biopsi were excluded

${ }^{\mathrm{b}} \mathrm{HR}$, hazard ratio; CI, confidence interval;

${ }^{\mathrm{c}}$ Multivariable analysis were adjusted for sex, age, period of diagnosis, site of primary tumour, histogenetic type, tumour thickness, Clark's level of invasion and tumour ulceration. 54 patients with missing values were excluded. The $\chi 2$ values from the multivariable analysis were: Tumour thickness (32.8), sex (13.2), histogenetic type (12.6), age (7.8), Clark's level of invasion (5.7), Tumour ulceration (4.7), period of diagnosis (1.6) and site of primary tumour (0.1). 